\title{
Guiding Massachusetts Toward an Age-Friendly Future
}

\author{
By Charlie Baker
}

$T_{\mathrm{d}}^{\mathrm{n}}$ he United States needs to think differently about aging, and in Massachusetts we are doing just that. We are focused on ensuring that those who raised families here and strengthened our communities continue to contribute their energy, experience, and talents where they live, to make Massachusetts the most age-friendly state.

Ensuring that the commonwealth remains a great place to grow up and grow old has been a priority for my administration. In April 2017, I established the first ever Governor's Council on Aging in Massachusetts to provide advice on how we can promote healthy aging. Like most states, our population is getting older. Today, there are more people over the age of 60 than under the age of 20 living in the Bay State. Older adults are the largest and fastest growing group, and it is estimated that they will make up 23 percent of the Massachusetts population by 2035. I see this demographic shift as an incredible opportunity because as I travel across the commonwealth and visit with older adults. I see them active, engaged, and ramping up - rather than ramping down - their contributions to the community.

That's why I created a council rich with individuals with expertise in not only aging but also business, nonprofits, academia, health care and philanthropy. The council traveled throughout Massachusetts and heard from hundreds of residents. Last April, I announced 10 initial priorities based on the council's work and, half a year later, the council is off to a good start in the right direction:

- Declaring Massachusetts an age-friendly state: Massachusetts is only the second state in the nation to join AARP's network of age-friendly states.

- Including age-friendly best practices in the Community Compact Program: Community Compacts are agreements between the state and local municipalities to support local projects of shared interest using best practices developed at the local level. Through this program, cities and towns can receive state funding to support their age-friendly work.

- Promoting the designation of age-friendly employers and practices that support mature workers and workers who are caregivers: This is a competitive opportunity for Massachusetts. Older workers represent the largest pool of available talent in our workforce today. We need to tap that potential and ensure that employers understand the value that mature workers bring to the table.

- Increasing participation in employer-sponsored retirement plans and options for those without access to such plans: Along with helping older workers enter and remain in the workforce, we need to find new ways to help people of all ages save for their later years. The sooner we can help people plan, the better off it will be for them, their families, and our Commonwealth.

- Supporting caregivers through increased information and awareness efforts: My administration has begun to make resources and information for family caregivers easier to find and access through our state website and through MassOptions, a dedicated aging and disability call center that connects people with state, local, and nonprofit agencies that offer services to help them.

- Promoting and updating property tax deferral programs-which can allow older people to stay in their homes and communities longer: Helping older residents on fixed incomes tap into the equity of their homes is an option in nearly all of our 351 communities. However, these tax deferral programs are not well understood, nor are they utilized at significant levels. The council is focused on updating and raising awareness about this option.

- Considering options, including new sources of capital, for increasing production of accessible, affordable, service-enriched housing: My administration filed major legislation to create a Housing Choice Initiative to help create 135,000 housing units over the next seven years. We were proud to have AARP Massachusetts' support and look forward to continuing our work on this important issue. Separate from the legislation, my administration has awarded more than $\$ 10$ million in recent months to encourage and empower municipalities to plan and build the diverse housing stock that the commonwealth needs to continue to thrive.

- Scaling and replicating successful Age-Friendly pilots, such as ride-sharing transportation options: Becoming age-friendly doesn't mean reinventing the wheel. We can expand successful 


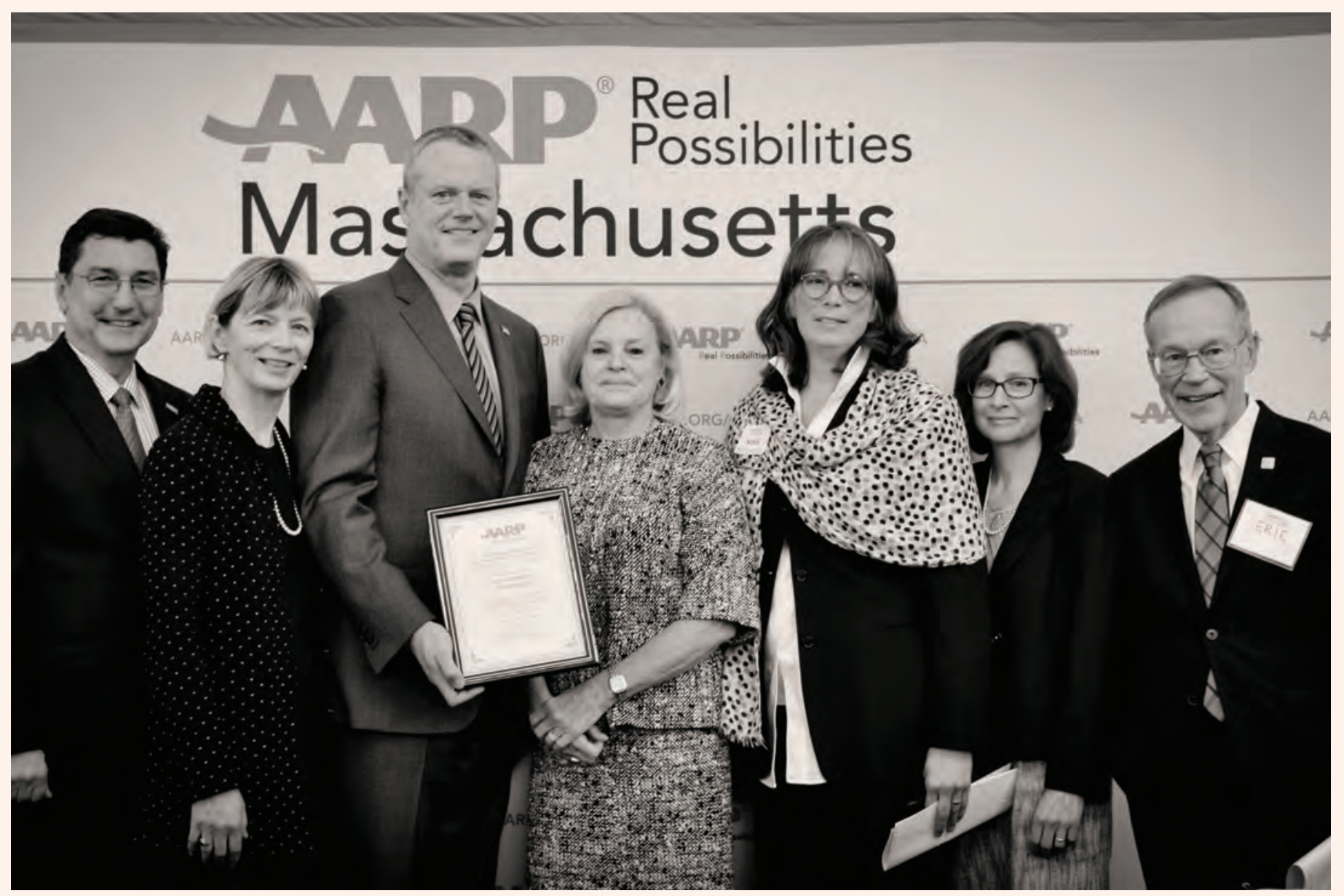

pilot projects, like our ride-hailing demonstrations with Uber and Lyft. We can also learn from others deeply engaged in age-friendly work in our local communities, other states, and even other countries.

- Becoming the Silicon Valley for innovative technology, products, and services related to aging: Many companies in Massachusetts are on the cutting edge of creating technologies and services to help people maintain their independence as they age. We are working to leverage the state's research and innovation sectors to help improve quality of life for older people everywhere.

\section{- Starting to change perceptions} and addressing ageism: To think differently about aging, we have to do more than think. We have to understand, talk, and act in a way that shows we value people of all ages and, concerning older adults, that we value not only their contributions of yesterday but what they can offer today and tomorrow.
In addition to the important work of the council, my administration has funded Massachusetts' Protective Services Program at the highest level ever, provided the highest level of state funding ever for Councils on Aging throughout our state, and implemented budget increases for Elder Affairs each year since 2015.

I also had the honor of signing a groundbreaking, first-in-the-nation law to improve care and treatment for the more than 130,000 Massachusetts residents living with Alzheimer's disease and other forms of dementia. This new law will enhance efforts to train frontline caregivers and will help families prepare for and manage the effects of Alzheimer's.

Of course, we have not been able to do any of this alone. Working together with strong partners such as AARP Massachusetts, the Tufts Health Plan Foundation, the Massachusetts Healthy Aging Collaborative, and many others, Massachusetts is creating a road map for a future that supports all our residents, both now and as they grow older and continue to thrive.
Governor Charlie Baker and other state and national leaders formally mark Massachusetts' membership in AARP's Network of Age-Friendly States. Pictured from left: Michael Festa, AARP Massachusetts state director; Mass. Health and Human Services Secretary Marylou Sudders; Governor Baker; Eileen Connors, co-chair of the Governor's Council to Address Aging in Massachusetts; Nora Moreno Cargie, President, Tufts Health Plan Foundation; Mass. Secretary of Elder Affairs Alice Bonner; and Eric J. Schneidewind, President, AARP Board of Directors

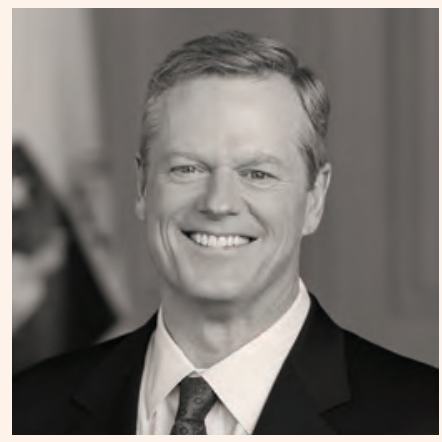

Charlie Baker

GOVERNOR OF MASSACHUSETTS UNITED STATES 